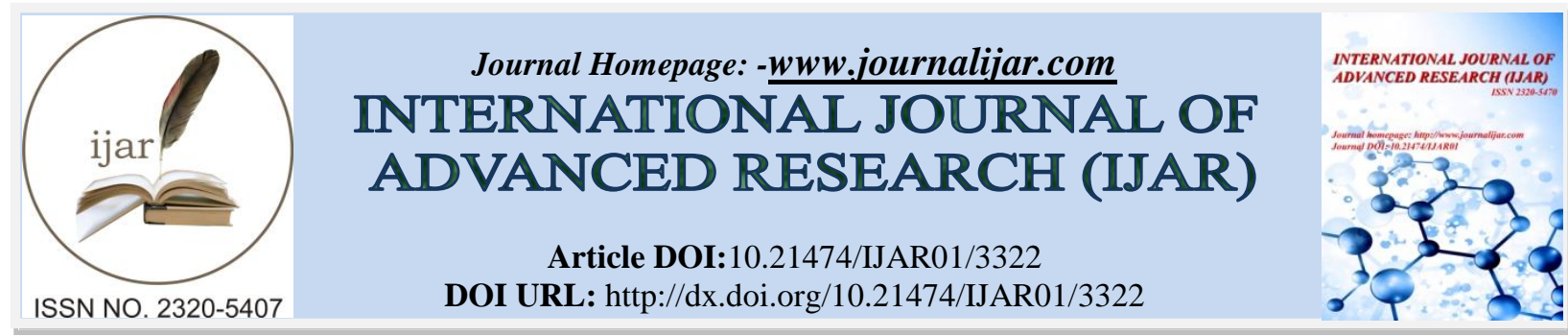

RESEARCH ARTICLE

\title{
ANTIBIOTICS USE AND MISUSE IN UPPER RESPIRATORY TRACT INFECTION PATIENTS: KNOWLEDGE, ATTITUDE AND PRACTICE ANALYSIS IN UNIVERSITY HOSPITAL, SAUDI ARABIA.
}

\author{
"Waseem Hajjar', Sara Al-khelb², Sarah Al-Mutairi" and Norah Al-Refayi². \\ 1. Assistant Professor \& Consultant Thoracic Surgeon. \\ 2. Medical intern.
}

\section{Manuscript Info}

Manuscript History

Received: 23 December 2016

Final Accepted: 20 January 2017

Published: February 2017

Key words:-

Antibiotics, awareness, misuse, upper respiratory tract infection.

\section{Abstract}

Background: Excessive use of antibioticsamong general public is a topic of global concern. The present study aimed to assess the awareness and causes of antibiotics use and misuse in patients with upper respiratory tract infections.

Methods: This cross-sectional hospital-based survey was conducted in the Primary Care Department, College of Medicine, King Saud University Riyadh, Saudi Arabia during the period Jan 2014 to Dec 2015. In this study, a well-establishedself-administrated questionnairewas randomly distributed to the patients suffering from URTI visiting at King Khalid University Hospital, Riyadh, Saudi Arabia. The questionnaire consisted of 3 parts;demographic variables, knowledge, beliefs and behaviors toward antibiotic use and misuse. Descriptive statistics were used for the analysis of data.Out of 420 collected responses, we included 400 and the remaining 20 were excluded.

Results: The results show that $45.5 \%$ of participants used antibiotics without prescription $(\mathrm{p}=0.050)$ and $10.8 \%$ used it over a pharmacist's advice $(\mathrm{p}=0.030) .17 .3 \%$ participants forced the physicians to prescribe antibiotic and $22 \%$ patients stopped taking antibiotics when they felt better $(\mathrm{p}=0.007)$. Moreover, $45 \%$ had the antibiotic stocks at home in case of emergencies. In addition, $16.8 \%$ were ignoring the instructions when taking antibiotics (p-0.004). $12 \%$ of the participants denied that an antibiotic could cause an allergic reaction ( $\mathrm{p}-0.054)$ and a similar percentage of participants (12\%) believed that the effectiveness of the treatment would not be affected if a full course of antibiotic is not completed $(\mathrm{p}=0.029) .7 .2 \%$ of the participants with high educational level believed that all antibiotics do not cause side-effects $(\mathrm{p}=0.002)$ and $17.8 \%$ of them believed that if symptoms were improving the antibiotic course can be interrupted without completing (p-0.037).

Conclusion:It is concluded that misconceptions exist about the use and indications of antibiotics. Lack of knowledge regarding antibiotic resistance and risks associated with use of antibiotics was prevalent. It is suggested that more interaction is required between physicians and patients, and involvement of both print and electronic media to improve the antibiotics knowledge and practices among community and

Corresponding Author:-Waseem Hajjar. 
consequently, control the problems of antibiotics misuse.

Copy Right, IJAR, 2017,. All rights reserved.

\section{Introduction:-}

Upper respiratory tract infections are the most prevalent infectious diseases in many societies and are one of the major reasons that patients visit the primary care clinics especially during the winter. Both bacteriological and viral microorganisms are etiological factors contributing to the development of upper respiratory tract infections ${ }^{1}$. However, most of them are caused by viruses, in which antibiotics are not needed ${ }^{2,3,4}$. Respiratory system conditionsare the most common cause for antibiotics prescription ${ }^{5,6}$.Several studies showed that physicians practice in prescribing antibiotics in such cases could be related to the physician response to the patient pressure ${ }^{7,8,9}$.In addition, over-prescription practices have been attributed to vague diagnosis and the fear of inadequate level of health care.Antibiotics misuse in cases where no definite clinical benefits from them can lead to adverse effects $^{10,11,12}$. The likelihood of antibiotics misuse by the public can be linked to the widespread glitches in the information about antibiotics. The general lack of knowledge and the poor awareness among the public with regard to the proper use of antibiotics and its indications have been documented.

There is a common public's misunderstanding such as the use of antibiotics can help in faster recovery and in the prevention of further illnesses in common conditions like upper respiratory tract infections ${ }^{13,14}$. The knowledge, attitudes and behaviors differ from one community to another. Limited literature is available from the Middle East Region addressing such topics ${ }^{14-15}$. However, still there is a great gap in the knowledge to understand the proper use of antibiotics. Therefore, this study aims to assess knowledge, attitudes and beliefs regarding antibiotics use and its effectiveness for upper respiratory tract infections in Riyadh, Saudi Arabia.

\section{Research Methodology:-}

Study Design:This cross-sectional hospital-based survey was conducted in the primary care department, King Khalid University Hospital, College of Medicine, King Saud University Riyadh, Saudi Arabia during the period Jan 2014 to Dec 2015. King Khalid University Hospital is one of the largest and leading university teaching hospitals, located in the capital city of the Kingdom of Saudi Arabia. The hospital provides primary, secondary and tertiary health care services to all citizens over the country and from Gulf region.

The targetedpopulation was adults from 16 years of age and above. A total of 420 well-structured English language questionnaires were distributed, 400 patients suffering fromURTI completed the questionnaires were included while the remaining 20 were excluded due to incomplete filling or double answers, giving a response rate of $95.24 \%$ among them $48 \%$ were males and $51 \%$ were females.

The questionnaire was formed based on the questions taken from previous studies and edited to suit the objectives ${ }^{2}$ 14, 16,17. A pilot study was conducted to test the validity of the questionnaire. The final version of the questionnaire contained 33 questions divided into four main parts. The first part was about demographic features. The second part was designed to assess recent antibiotics usage in the last year, the reason of the usage, and whether it was used with or without a prescription. The third part contained eleven statements with (Yes-No-Not sure) options to assess participant general knowledge and attitude about antibiotics. Statements included role of antibiotics, harmful effects of antibiotics and completion of treatment course. The fourth part was designed to evaluate the behaviors toward antibiotics use. This part consisted of nine statements about the antibiotics usage in common cold, patient's expectation from the physicians, patient's compliance, sharing and keeping antibiotics for emergency cases and others. Responses were taken also in (Yes-No-Not sure) pattern. One additional question was asked about the participants' source of information about antibiotics. Options were (from the doctor-pharmacist-internet- mediarelatives and friends).A written consent was taken from all respondents before answering the questionnaires. Participants' anonymity was assured by assigning each participant with a code number for the purpose of analysis only. No incentives or rewards were given to participants. Data collection wasconducted by research team from December 2013 to February 2014. Collected data were tabulated and analyzed by using SPSS software version 21 (SPSS Inc Chicago, IL). The prevalence of antibiotic use, misuse and its awareness were determined by comparing outcome measures. Numerical variables were reported as the mean \pm standard deviation. The statistical significance was defined as p-value $<0.05$. 
Ethical approval: Study was approved by the Institutional Review Board, Department of Family and Community Medicine, College of Medicine, King Saud University, Riyadh.

\section{Results:-}

Demographic characteristic of respondents: A total of 420 questionnaires were distributed at the primary care clinic, 400 completed questionnaires were included while the remain 20 were excluded due to incomplete filling or double answers, giving a response rate of $95.24 \%$ among them $48 \%$ were males and $51 \%$ were females. Participants were compared according to their demographic parameters: age, nationality, marital status, educational level, employment status, antibiotics usage per year, and recent antibiotics usage within one year (Table 1). Among the respondents, $37.5 \%$ were in the age group of $26-35$ years (p-0.320), $62.5 \%$ were married $(\mathrm{p}-0.057), 57.5 \%$ were well educated (College or University) (p-0.000), and $46 \%$ were employed (p-0.000). About $70.3 \%$ of the individuals used antibiotics recently (p-0.578) and 46\% used 2-4 times per year (p-0.408). Respiratory illnesses were the third highest cause of the use of antibiotics, other causes are shown in Figure1. Data on respondent's knowledge, behavior and attitude towards antibiotics use are presented in Table 2.

The impact of age on use of antibiotics: $45.5 \%$ of participants were using antibiotics without prescription (p$0.050)$ and $10.8 \%$ using the antibiotics over a pharmacist's advice (p-0.030). $17.3 \%$ of all age groups had forced the doctor to prescribe antibiotic, $6.3 \%$ of them were between $26-35$ years (p-0.014). Furthermore, respondents who stopped taking antibiotics when they felt better were higher in the age group of 26-35 years, with a given percentage of $22 \%$ out of $51.7 \%$ (p-0.007). Moreover, $45 \%$ of all age groups agreed on keeping the antibiotic stocks at home in cases of emergencies, with a higher percentage in the age group between 16-35 years (p-0.010). In addition, 16.8\% were found to be ignoring the instructions on the label when taking antibiotics (p-0.004). (Table2).

The impact of gender on use of antibiotics: In order to further explore the influence of gender in relation with the respondent's knowledge, attitude and behavior regarding usages of antibiotics. Knowledge and belief results were less remarkable than behavioral. $12 \%$ of the participants denied that antibiotics could cause an allergic reaction (p0.054). A similar percentage of participants (12\%) among them $6.3 \%$ were males and $5.8 \%$ were females believed that the effectiveness of the treatment would not be affected if a course of antibiotic was not completed (p-0.029). On the other hand, behavioral questions' results revealed that $7 \%$ of male participant out of $10.3 \%$ obtained antibiotics without prescription (p-0.042) and the same percentage was recorded for male getting antibiotics over a pharmacist's advice. Moreover, males and females who took antibiotics when they suffered with common cold represented $24.6 \%$ and $19 \%$ respectively (p-0.014). However, $10.3 \%$ of male and $7 \%$ of female enrolled in the study used to force the doctor to prescribe to them antibiotics when they felt sick ( $\mathrm{p}-0.043)$. The majority of both genders showed significant result in keeping antibiotic stocks at home in case of emergency (44.9\%) (p-0.006) and also using the leftover antibiotics for a respiratory illness (9\%) (p-0.001)(Table 3).

The impact of educational level on use of antibiotics: The analysis of educational levels' indicated that $7.2 \%$ of the participants with high educational level (College and University) believed that all antibiotics do not cause sideeffects (p-0.002). Furthermore, $17.8 \%$ of them considered that if their symptoms were improving they could interrupt the course of the antibiotic without completing it (p-0.037). As a result, their percentage was the highest among all educational levels in stopping the intake of the antibiotic after feeling better (41.3\% out of 51.7\%) (p0.012). (Table 4).

Regarding antibiotics misuse prevalence, we calculated the percentage of behavior-related questions, $30.61 \%$ of the study participants' showed misuse toward antibiotics. (Figure 2). Figure 1 shows the causes of use of antibiotics among the participants were the relief of inflammation 24\%; while $22 \%$ used the antibiotics for the relief of fever. Respiratory illness took the third place with a percentage of $21 \%$, pain came after with a value of $10 \%$. Urinary tract infection, skin diseases and wound showed percentage of 7\%, 4\% and 2\% respectively. Furthermore, figure 2 shows that participants' sources of information about antibiotic were primarily doctors followed by pharmacists. The other sources were Internet, relative and friends, media, and finally the news and magazine (Fig 2). 
Table 1:-Demographic characteristic of the participants

\begin{tabular}{|l|l|l|l|l|l|}
\hline Parameter & Frequency & Percent $\%$ & Male & Female & $P$ value \\
\hline Age (years) & & & & & \\
$16-25$ & 83 & 20.8 & $11.8 \%$ & $9 \%$ & \\
$26-35$ & 150 & 37.5 & $16.3 \%$ & $21.3 \%$ & 0.320 \\
$36-45$ & 89 & 22.3 & $11 \%$ & $11.3 \%$ & \\
$46-55$ & 52 & 13.3 & $5.5 \%$ & $7.3 \%$ & \\
$>55$ & 26 & 6.5 & $3.5 \%$ & $3 \%$ & \\
\hline Nationality & & & & & 0.187 \\
Saudi & 375 & 93.8 & $46.1 \%$ & $48.1 \%$ & \\
Non-Saudi & 23 & 5.8 & $2 \%$ & $3.8 \%$ & \\
\hline Marital Status & & & & & \\
Single & 121 & 30.3 & $15.2 \%$ & $15.4 \%$ & \\
Married & 250 & 62.5 & $31.4 \%$ & $31.6 \%$ & 0.057 \\
Divorced & 15 & 3.8 & $1.3 \%$ & $2.5 \%$ & \\
Widowed & 10 & 2.5 & $0.3 \%$ & $2.3 \%$ & \\
\hline Educational level & & & & & \\
Elementary school or lower & 49 & 12.3 & $1.3 \%$ & $11 \%$ & \\
Secondary school & 27 & 6.8 & $2.3 \%$ & $4.5 \%$ & 0.000 \\
High school & 94 & 23.5 & $10 \%$ & $13.5 \%$ & \\
College or over & 230 & 57.5 & $34.6 \%$ & $22.8 \%$ & \\
\hline Employment status & & & & & \\
Employed & 184 & 46.0 & $35.3 \%$ & $10.5 \%$ & \\
Unemployed & 132 & 33.0 & $2.8 \%$ & $30.3 \%$ & 0.000 \\
Student & 60 & 15.0 & $6.8 \%$ & $8.3 \%$ & \\
Retired & 24 & 6.0 & $3.3 \%$ & $2.8 \%$ & \\
\hline Antibiotics usage per Year & & & & & \\
Once & 123 & 30.8 & $14.5 \%$ & $16.3 \%$ & \\
2-4 times & 184 & 46.0 & $23.6 \%$ & $22.3 \%$ & 0.408 \\
More than 4 times & 93 & 23.3 & $10 \%$ & $13.3 \%$ & \\
\hline Recently used antibiotics (One & & & & & \\
Year) & 281 & 70.3 & $34.5 \%$ & $36.3 \%$ & 0.578 \\
Yes & 117 & 29.3 & $13.4 \%$ & $15.9 \%$ & \\
No & & & & \\
\hline
\end{tabular}

Table 2:-Comparison of age group of participants with regard to knowledge, beliefs and attitudes towards antibiotic use and awareness

\begin{tabular}{|l|l|l|l|l|l|l|l|l|}
\hline Age & Yes $\backslash$ No & Not Aware & $16-25$ & $26-35$ & $36-45$ & $46-55$ & $>55$ & $P$ value \\
\hline $\begin{array}{l}\text { Antibiotics used by } \\
\text { prescription No }\end{array}$ & $45.5 \%$ & $12.3 \%$ & $15.5 \%$ & $9.3 \%$ & $5 \%$ & $3.5 \%$ & 0.050 \\
\hline $\begin{array}{l}\text { Antibiotics used by } \\
\text { pharmacist's advice }\end{array}$ & Yes & $10.8 \%$ & $4.3 \%$ & $3.3 \%$ & $1.5 \%$ & $1.3 \%$ & $0.5 \%$ & 0.030 \\
\hline $\begin{array}{l}\text { I force to doctor to } \\
\text { prescribe me antibiotics } \\
\text { when I sick Yes }\end{array}$ & $17.3 \%$ & $5.3 \%$ & $6.3 \%$ & $4.3 \%$ & $1.5 \%$ & $0 \%$ & 0.014 \\
\hline $\begin{array}{l}\text { I normally stop taking } \\
\text { antibiotics when I start } \\
\text { feeling better Yes }\end{array}$ & $51.7 \%$ & $12.8 \%$ & $22 \%$ & $10.5 \%$ & $4 \%$ & $2.5 \%$ & 0.007 \\
\hline $\begin{array}{l}\text { I normally keep } \\
\text { antibiotic stocks at home } \\
\text { in case of emergency }\end{array}$ & Yes & $45 \%$ & $12.5 \%$ & $17.8 \%$ & $8 \%$ & $5 \%$ & $1.8 \%$ & 0.010 \\
\hline $\begin{array}{l}\text { I take antibiotics } \\
\text { according No the } \\
\text { instruction on the label }\end{array}$ & & $16.8 \%$ & $2.3 \%$ & $5.8 \%$ & $3.3 \%$ & $3 \%$ & $2.5 \%$ & 0.004 \\
\hline
\end{tabular}


Table 3:-Comparison of gender in relation with participant's knowledge, beliefs and attitudes towards antibiotic use and awareness

\begin{tabular}{|l|l|l|l|l|l|}
\hline Gender & Yes $\backslash$ No & NotAware & Male & Female & $P$ value \\
\hline Antibiotics use without prescription & Yes & $10.8 \%$ & $6.8 \%$ & $4 \%$ & 0.042 \\
\hline Antibiotics can cause allergic reaction & No & $12 \%$ & $5.8 \%$ & $6.3 \%$ & 0.054 \\
\hline $\begin{array}{l}\text { The effectiveness of treatment reduced if } \\
\text { a full course of antibiotic is not } \\
\text { completed }\end{array}$ & No & $12 \%$ & $6.3 \%$ & $5.8 \%$ & 0.029 \\
\hline $\begin{array}{l}\text { When get a cold, I used to take } \\
\text { antibiotics to help me get better more } \\
\text { quickly }\end{array}$ & Yes & $43.6 \%$ & $24.6 \%$ & $19 \%$ & 0.014 \\
\hline $\begin{array}{l}\text { I expect antibiotics to be prescribed by } \\
\text { my doctor if I suffer from symptoms of } \\
\text { common cold }\end{array}$ & Yes & $56.4 \%$ & $30.3 \%$ & $26.1 \%$ & 0.032 \\
\hline $\begin{array}{l}\text { I usually force my doctor to prescribe me } \\
\text { antibiotics when I get sick }\end{array}$ & Yes & $17.3 \%$ & $10.3 \%$ & $7 \%$ & 0.043 \\
\hline $\begin{array}{l}\text { I normally keep antibiotic stocks at home } \\
\text { in case of emergency }\end{array}$ & Yes & $44.9 \%$ & $23.6 \%$ & $21.3 \%$ & 0.006 \\
\hline $\begin{array}{l}\text { I use leftover antibiotic for a respiratory } \\
\text { illness }\end{array}$ & Yes & $9 \%$ & $4.8 \%$ & $4.3 \%$ & 0.001 \\
\hline
\end{tabular}

Table4:- Comparing the education level of participants with antibiotic awareness

\begin{tabular}{|l|l|l|l|l|l|l|l|}
\hline Educational Level & Yes/ No & Not Aware & $\begin{array}{l}\text { Elementary } \\
\text { school }\end{array}$ & $\begin{array}{l}\text { Secondary } \\
\text { school }\end{array}$ & $\begin{array}{l}\text { High } \\
\text { school }\end{array}$ & $\begin{array}{l}\text { College or } \\
\text { University }\end{array}$ & $P$ value \\
\hline $\begin{array}{l}\text { Antibiotics do not } \\
\text { cause side effects }\end{array}$ & Yes & $15.8 \%$ & $4.5 \%$ & $1 \%$ & $3 \%$ & $7.2 \%$ & 0.002 \\
\hline $\begin{array}{l}\text { Stop taking a full } \\
\text { course of antibiotic on } \\
\text { improving Yes } \\
\text { symptoms of }\end{array}$ & $36.5 \%$ & $6.5 \%$ & $3 \%$ & $9.3 \%$ & $17.8 \%$ & 0.037 \\
\hline $\begin{array}{l}\text { Normally stop taking } \\
\text { antibiotics Yes } \\
\text { feeling better when }\end{array}$ & $51.7 \%$ & $7 \%$ & $3.5 \%$ & $15 \%$ & $26.3 \%$ & 0.012 \\
\hline
\end{tabular}

Fig 1:-Participants reseaons for the use of antibiotics

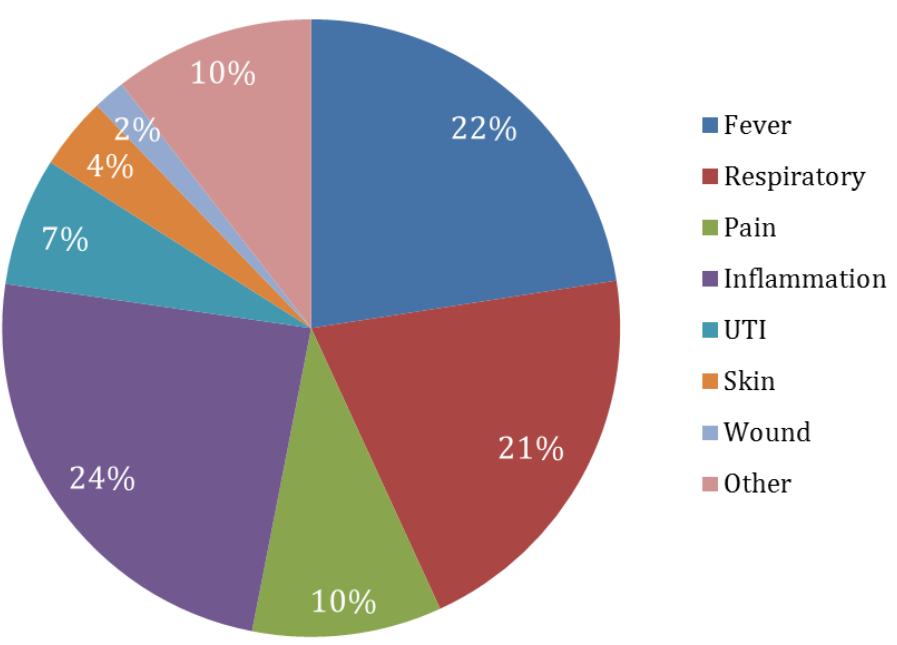


Fig 2:-Participants' source of information about the antibiotics

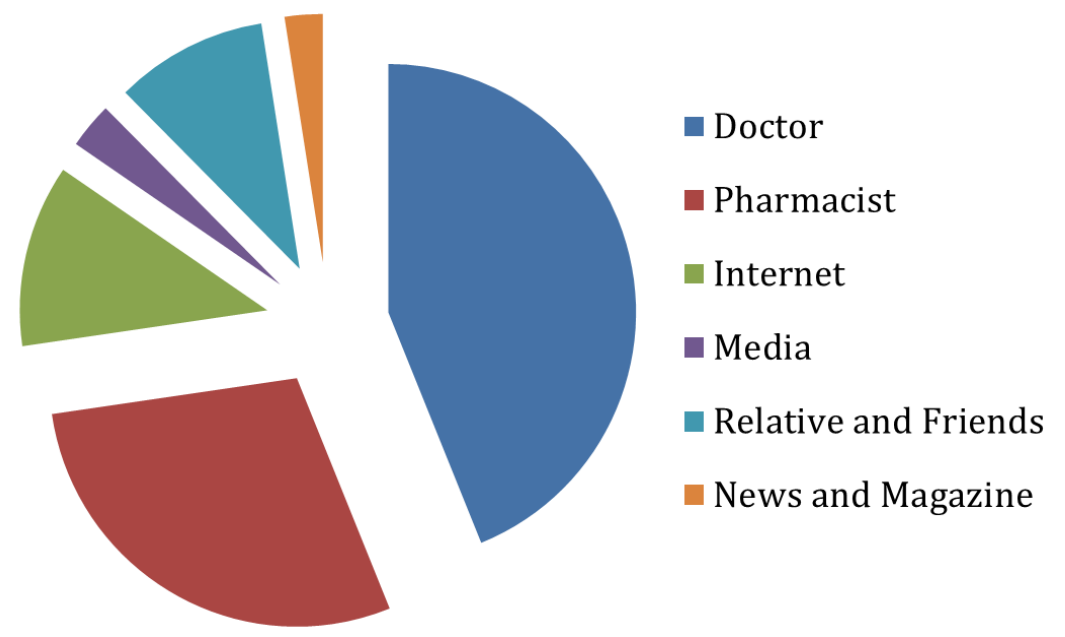

\section{Discussion:-}

Antibiotics misuse can lead to a wide range of adverse consequences. The patients' knowledge and beliefs about antibiotics can dramatically affect the way they use these medications. Therefore, it is necessary to assess the extent of patients' knowledge in order to reach the right interventions, which in turn guide the patients' behaviors and usage toward these drugs ${ }^{14}$. This study demonstrates that the majority of the participants were using antibiotics frequently from two to four times per year. Furthermore, 281 (70.3\%) of respondents had recently used antibiotics within the last year. In addition, the percentage reported in this study was even higher than the percentage reported by a study conducted in Oman by Jose et al., ${ }^{14}$ in which only $66 \%$ of the respondents had used antibiotics recently within the last year ${ }^{14}$. The causes for using antibiotics varied from one respondent to the other with higher percentages given to reason for inflammation (24\%), fever (22\%), and respiratory illness $(21 \%)$. In terms of knowledge, $55.8 \%$ of participants agreed that antibiotics could be used to treat viral infections compared to $46 \%$ as reported by Curry et al., $2006^{10}$. This confirms the lack of knowledge of the participants and their inability to recognize the differences between bacteria and viruses relateddiseases. The reason behind this can be due to the use of the word "germs" when counseling and seeking a medical advice instead of using the words "bacteria" or "viruses" ${ }^{2}$. Moreover, the majority of respondents believe that antibiotics can also be used to relieve pain and fever. While, when the participants questioned directly about their behaviors toward antibiotics, $79.3 \%$ had a correct behavior in disagreement to the statement about "I usually force my doctor to prescribe me antibiotics when I get sick". Nevertheless, $56.3 \%$ were expecting their doctors to prescribe them an antibiotic when suffering from common cold. This can be attributed to the large number of prescriptions for antibiotics in respiratory viral infections, which in most of the cases are selflimiting. This leads to the impact on the general belief that such medicines are effective against these diseases. Consequently, such incorrect belief contributes to the raising of the expectations that antibiotics are inappropriate treatment for common colds ${ }^{2}$. The findings in current study have shown that the vast majority of participants $\mathbf{( 7 4 . 3 \% )}$ were more aware that if an antibiotic's full course was interrupted, the effectiveness will decrease in comparison with Oh et al., 2011 where $71.1 \%$ only had correct answer ${ }^{2}$. However, $51.8 \%$ agreed that they would stop using antibiotics when they start feeling better. This showed the inadequacy of knowledge wherein most people do not understand the real cause and the actual significance of completing the antibiotic's full course ${ }^{2}$. The results of this study showed the need of an urgent intervention by educating people through annual campaigns about antibiotics' uses, and the importance of compliance. Moreover, it is important to clarify the differences between bacteria and viruses, causes of common colds, and how to alleviate their symptoms apart from antibiotics' usage. The analysis of awareness based on demographics showed significant correlation between misuse and three main factors which are age, gender, and educational level. It was found that those in the age group between 26-35 years were behaving incorrectly more than the other age groups. Furthermore, it had been shown that after the age of 35 with each additional increase in the age, individuals become more aware and tend to have a more positive attitude toward antibiotics. As a result, this guides us to direct these campaigns to this age group in particular and the other age groups in general. Moreover, in this study females seemed to be behaving better than males in several ways like in using antibiotics without prescriptions, keeping stocks, and using leftover antibiotics. We can attribute this result to the females' nature where they are more careful and practical than men when it comes to their lives ${ }^{18}$.As reported, there is correlation between misusing antibiotics and high educational level (College and University). 
When the participants questioned directly about their source of information about antibiotics, physicians were occupying the first place followed by the pharmacists. Therefore, it is also important to alert physicians to educate people about the rational uses of antibiotics, its adverse consequences, common cold etiology, and its management. In addition, pharmacists should be willing to refuse any selling of an antibiotic without prescription. Moreover, health officials can set policies to limit these actions globally.

Strengths and limitations:The strengths of this study are represented in several aspects. It was conducted in a tertiary care hospital that provides services to all citizens coming from different regions in Saudi Arabia. The questionnaire was distributed equally between both genders. However, there are some limitations in the present study. First of all, there was a high percentage of participants with high educational level (Collegeand University) this could be due to shortage in the number of options provided in the questionnaire where diploma degree holders were not included. As a result, participants who hold diploma may choose "College and University" option. Therefore, increasing the number of options would have defined another representative. Second, recall bias might affect the results as some of the questions depended on recalling. Moreover, the results depended on the honesty and the understanding of the respondents, as it was a self-reported questionnaire. Even though King Khalid University Hospital attracts large number of citizens coming from different regions, this study can be generalized to the capital city Riyadh as Kingdom of Saudi Arabia has different culture in various regions. Furthermore, it would be a supporting study to future researches conducted in other regions as health related studies and policies supporting each other. Finally, we recommend starting a large-scale research covering the whole nation in order to represent the data optimally.

\section{Conclusion:-}

It is concluded that, misconceptions exist about the use and indications of antibiotics in the community. This study highlights the need to educate patients regarding antibiotic use and the consequences of misuse. Which diseases actually require antibiotics, why full daily doses must be respected, risk of keeping part of a course for future uncontrolled use and need of a prescription for getting antibiotics from the pharmacist are some of the issues to be discussed with the patients. The majority of participants who show misuse were from age group 26-35, that makes them the main target for future awareness and educational programs to improve the knowledge, attitude and behavior toward antibiotic uses. Interaction is required between physicians and patients and involvement of both print and electronic media may help to improve the antibiotics knowledge and practices in community and consequently control the antibiotics misuse.

\section{Recommendations:-}

The community needs well-planed educational campaigns to raise the awareness of antibiotic uses and its adverse effects. Moreover, we recommend that similar studiesshould be held in different regions in Saudi Arabia. In addition, it is important to have a standard polices regarding antibiotics' selling, wherein getting any antibiotic without prescription should not be allowed. Furthermore, since the majority of participants get their information from their doctors, educating patients by physicians about antibiotic uses, its role in treating etiologies of upper respiratory tract infections and its adverse effects will have a great impact on patients' knowledge and behavior. Major changes in prescribing practice supported by a national information campaign would be beneficial to reduce patient's expectation from antibiotics and to raise awareness about antibiotic resistance.

\section{Acknowledgments:-}

The authors are thankful to the Deanship of Scientific Research, King Saud University, Riyadh, Saudi Arabia for supporting the work through research group project (RGP-VPP 181). We are also thankful to Dr. Raju K Mandal for his valuable suggestions regarding the questionnaire and Dr. Philip Feeley for his assistance in statistical analysis.

Disclosure: The funders had no role in study design, data collection and analysis, decision to publish or preparation of the paper.

Competing Interests: The authors declare no competing financial interests.

Funding disclosure: Deanship of Scientific research king SaudUniversity, Riyadh, SaudiArabia Research project (RGP-VPP 181). 
Authors' Contributions: WH, SAN designed the study, helped in manuscript writing; SAK KAM, NAR performed the literature review and data collection; SAM wrote the manuscript. All authors reviewed and approved the manuscript.

Data Availability: All the relevant data are available in the manuscript.

\section{References:-}

1. Bosch AA, Biesbroek G, Trzcinski K, Sanders EA, Bogaert D. Viral and bacterialinteractions in the upperrespiratorytract.PLoSPathog. 2013; 9:e1003057.

2. Oh, A., Hassali, M., Al-Haddad, M., Sulaiman, S., Shafie, A. and Awaisu, A. Public knowledge and attitudes towards antibiotic usage: a cross-sectional study among the general public in the state of Penang, Malaysia. J Infect Dev Ctries, 2011; 5:338-347.

3. Zyoud SH, Abu Taha A, Araj KF, et al. Parental knowledge, attitudes and practices regarding antibiotic use for acute upper respiratory tract infections in children: a cross-sectional study in Palestine. BMC Pediatrics. 2015; $15: 176$

4. Cals J, Boumans D, Lardinois R, Gonzales R, Hopstaken R, Butler C, Jan Dinant G. Public beliefs on antibiotics and respiratory tract infections: an internet -based questionnaire study. British Journal of general practice. 2007;57: 942-947.

5. Murphy M, Bradley CP, Byrne S. Antibiotic prescribing in primary care, adherence to guidelines and unnecessary prescribing - an Irish perspective.BMC Family Practice. 2012;13:43

6. 6) Shaw A, Sharp D, Hay AD. Towards a better understanding of patients' perspectives of antibiotic resistance and MRSA: a qualitative study. Fam Pract. 2008; 25:341-8.

7. Shehadeh M, Suaifan G, Darwish R, Wazaify M, Zaru L, and Alja'Fari S. Knowledge, attitudes and behavior regarding antibiotics use and misuse among adults in the community of Jordan. A pilot study.Saudi Pharm $\mathrm{J}$. 2012;20:125-133

8. Awad A, Aboud E. Knowladge, Attitude and practice towards Antibiotic use among the public in Kuwait. PLOS ONE. 2015; 10: e0117910.

9. Gualano, M. R., Gili R., Scaioli G., Bert F., and Siliquini R. General population's knowledge and attitudes about antibiotics: a systematic review and meta-analysis. Pharmacoepidemiol Drug Saf. 2014; 24:2-10.

10. Curry M, Sung L, Arroll B, Goodyear-Smith F, Kerse N, Norris P. Public views and use of antibiotics for the common cold before and after an education campaign in New Zealand. N Z Med J. 2006; 119: 1233.

11. Rattinger GB, Mullins CD, Zuckerman IH, et al. A Sustainable Strategy to Prevent Misuse of Antibiotics for Acute Respiratory Infections. Manzoli L, PLoS ONE. 2012;7:e51147

12. Napolitano F, Izzo MT, Di Giuseppe G, Angelillo IF. Public Knowledge, Attitudes, and Experience Regarding the Use of Antibiotics in Italy. PLoS ONE. 2013; 8:e84177.

13. McNulty CA, Nichols T, French DP, Joshi P, Butler CC. Expectations for consultations and antibiotics for respiratory tract infection in primary care: the RTI clinical iceberg. The British Journal of General Practice. 2013;63:e429-e436

14. Jose J, Jimmy B, Alsabahi AG, Al Sabei GA. A studyassessingpublicknowledge, belief and behavior of antibiotic use in an Omani population. Oman Med J. 2013; 28:324-30.

15. Shariff A, Al Dhubiab BE, Al Nowis M, Al Haddad F, Al Omran N, Al Khuliteet H. Statistical investigation of patient factor in development of antibiotic resistance - A study in Eastern Province of Saudi Arabia. Int J Pharm Pharm Sci. 2013;5:151-156.

16. McNulty C, Boyle P, Nichols T, Clappison P, Davey P. Don't wear me out - the public's knowledge of and attitudes to antibiotic use. J AntimicrobChemother. 2007; 59: 727-738.

17. So Sun K, Seongmi M, Jung E. Public Knowledge and Attitudes Regarding Antibiotic Use in South Korea. J Korean AcadNurs. 2011; 41: 742-749.

18. Biswas M, Roy MN, Manik MIN, Hossain MS, Tapu STA, Moniruzzaman M, Sultana S. Self medicated antibiotics in Bangladesh: a cross-sectional health survey conducted in the Rajshahi City. BMC Public Health. 2014; $14: 847$. 